\title{
Perancangan Instalasi Interaktif
}

\section{Komposisi Musik Dan Visual}

\section{(Studi Kasus: Tari Saman)}

\author{
Grace Carolline, Hendy Hertiasa, Ary Setijadi Prihatmanto \\ Institut Teknologi Bandung
}

\begin{abstract}
On such era of globalization, we can't only focus on utilization of technological advances, we also have to look on the implementation and development of technological advances itself. Creativity of each individual is a basis in the birth of new innovations if supported by the proper technology. We expected the merger of technology and creativity, along with the local culture will be able to maintain the values and integrity of Indonesian national identity. As a case study, "Interactive Installation Design of Music and Visual Composition From Saman Dance" is one attempt to realize the above ideas. The result of the design of this interactive installation is a game tool for composing music and visual. Different from the preexisting games, on this game the user is the one who controls the system, not the opposite.
\end{abstract}

Keywords: Interactive Instalation, Interaction Design, Music, Visual, Saman Dance

\section{PENDAHULUAN}

Musik merupakan anugerah yang diberikan oleh Sang Pencipta kepada manusia. Unsur musik paling sederhana yang terdapat di dalam tubuh manusia adalah ketukan yang berupa detak jantung. Oleh sebab itu, musik tidak dapat dipisahkan dari manusia. Musik juga telah menjadi alat komunikasi bagi manusia sebelum lahirnya bahasa.

\section{Koentjaraningrat} memasukkan musik sebagai wujud dari salah satu unsur kebudayaan universal, yaitu kesenian. Manusia sebagai makhluk yang berbudaya tidak lain adalah makhluk yang senantiasa mendayagunakan akal budinya untuk menciptakan kebahagiaan, karena yang membahagiakan hidup manusia itu hakikatnya sesuatu yang baik, benar dan adil. Alfred L. Kroeber (1952) pun mengatakan bahwa 
beberapa aktivitas manusia yang melingkupi ilmu pengetahuan dan seni sesungguhnya berdasarkan pada suatu dorongan bermain (play impulse). Bila dianalogikan ke dalam seni sebagai elemen budaya, maka pernyataan Kroeber ini dapat dimaknai bahwa dorongan bermain sebetulnya adalah modal dasar untuk mengeksplorasi serta mengelaborasi berbagai potensi kreatif yang masih tersimpan sebagai pustaka hidup di dalam masyarakat yang memilikinya. Adapun faktor pendorong manusia dalam berkreasi adalah keinginan untuk mengekspresikan pikiran, perasaan, ide, gagasan, khayalan imajinasi, kepercayaan, keyakinan, kepribadian, atau pun sekedar kepuasan jiwa. Musik adalah sebuah bahasa yang mengekspresikan perasaan seseorang melalui rangkaian nadanada dalam bentuk lagu atau instrumentalia yang menyampaikan pesan penciptanya. Musik juga dikatakan sebagai rangkaian bunyi yang mempunyai nada-nada berdasarkan tata aturan untuk dinikmati melalui indera pendengaran. Musik juga telah digunakan sebagai penyampai karakteristik dari masing-masing masyarakat yang menggunakannya dan sekaligus bisa dijadikan media komunikasi untuk menciptakan serta memelihara identitas kelokalan yang ada di setiap kelompok masyarakat.
Di samping hakikat manusia sebagai makhluk yang berbudaya, manusia juga merupakan makhluk kreatif. Hal tersebut sangat berkaitan dengan perkembangan teknologi. Di era globalisasi ini, fokus tidak hanya terletak pada pemanfaatan kemajuan teknologi, melainkan pada penerapan serta pengembangan dari kemajuan teknologi tersebut yang dapat memicu kreativitas dalam melahirkan inovasi-inovasi.

Saat ini, perkembangan teknologi sangat berpengaruh terhadap perkembangan multimedia. Menurut Vaughan (2011), multimedia adalah kombinasi dari text, graphic, sound, animation dan video yang dikirim melalui komputer atau perangkat manipulasi elektronik atau digital lain. Multimedia interaktif adalah kombinasi dari elemen-elemen yang saling berhubungan dan dimanipulasi secara digital dimana disediakan kontrol terhadap konten dan interaksi tingkat tinggi bagi pemakai individu dan aplikasi multimedia. Ketika terdapat struktur elemen terkait dapat dinavigasi oleh user, multimedia interaktif menjadi hypermedia, yaitu media yang tidak hanya memuat teks saja, namun juga foto, audio dan video dan grafis komputer yang berhubungan dengan topik tertentu. Dalam Multimedia linear pengguna hanya sebagai penonton dan menikmati produk multimedia yang disajikan dari awal hingga akhir. Namun ketika user diberikan 
kontrol navigasi dan mengatur konten dan elemen yang ada, multimedia menjadi tidak linear dan pengguna menjadi interaktif. Seperti yang diterapkan dalam perancangan instalasi interaktif yang berjudul Oncé ini, user diberikan kontrol navigasi dan mengatur konten serta elemen yang ada.

Dengan menggunakan teknologi motion capture dan sensor Kinect, pemanfaatan multimedia tersebut adalah sebagai hiburan yang berupa game atau permainan interaktif komposisi musik dan visual. Menurut Jesse Schell (2008), game adalah sebuah struktur interaktif dari sebuah organisme atau sistem yang mengharuskan pemain untuk berjuang menuju sasaran atau tujuan. Dalam perancangan ini, sasaran atau tujuannya adalah menggabungkan elemen-elemen bunyi hasil eksplorasi dari musik Tari Saman menjadi sebuah komposisi musik utuh. Sementara itu, eksplorasi ragam hias kain kerawang Gayo yang dikenakan para penari Saman digunakan sebagai visualisasi dalam instalasi interaktif ini.

Cara berpikir individu yang kreatif, kiranya akan dapat membawa ide-ide baru ke tengahcakupannya secara global. Dari pertanyaan yang umum tadi, pertanyaan selanjutnya dipersempit untuk mendapatkan sesuatu yang lebih spesifik. Kemudian proses dilanjutkan tengah masyarakat sebagai sesuatu yang terlihat dan ternilai dari suatu perlakuan yang tidak hanya sekedar unik atau anomali dari sesuatu yang sudah ada sebelumnya. Selain dari itu, dorongan bermain yang terencana dan dirayakan ini, akan serta merta pula dapat mempertahankan keberlangsungan eksistensi dari manifestasi kreativitas sebagai bagian dari elemen budaya.

\section{METODE PENELITIAN}

Dalam perancangan instalasi interaktif ini metode penelitian yang digunakan adalah metode deskriptif-kualitatif, yaitu memaparkan situasi dan kondisi fenomena desain interaktif untuk permainan interaktif, khususnya instalasi interaktif komposisi musik dan visual hasil dengan studi kasus Tari Saman, serta user interface menurut perilaku desain, kegiatan, perilaku manusia terhadap lingkungan dan jasa-produk teknologi.

Metode penelitian dipaparkan secara sistematis, faktual dan akurat melalui pemaparan deduktif. Dalam melakukan perancangan instalasi interaktif ini diawali dengan pertanyaan yang umum atau luas

dengan melakukan observasi. Dari hasil observasi dilakukan analisis data dengan sumber dan referensi yang ada sesuai dengan kebutuhan dalam perancangan ini, yaitu menganalisis nyanyian pengiring 
Tari Saman, bunyi-bunyian yang dihasilkan dari gerakan tangan Tari Saman dan filosofi ragam hias kerawang Gayo. Tahap selanjutnya adalah menentukan metodemetode yang akan digunakan. Setelah itu metode-metode tersebut digabungkan dan diimplementasikan menjadi suatu rangkaian sistem instalasi interaktif. Setelah fungsi-fungsi dilengkapi maka dibuat work flow aplikasi untuk urutan proses sistem instalasi interaktif. Lalu dilakukan perancangan terhadap aset-aset komposisi musik dan visual dari data-data yang telah dikumpulkan dalam tahap observasi dan merancang user interface dan proses akhir melakukan optimasi pada sistem agar tujuan semula instalasi berhasil dicapai.

Proses perancangan instalasi interaktif komposisi musik dan visual hasil dengan studi kasus Tari Saman ini menekankan pada proses interaksi antara sistem dengan user, desain user interface, desain visual secara keseluruhan dan komposisi musik digital. Teoriteori yang berhubungan dengan perancangan instalasi interaktif ini dikumpulkan dan dianalisis untuk menghasilkan konsep sistem, serta konsep komposisi musik, visual dalam instalasi. Dari data-data yang telah dikumpulkan, dibuatlah storyboard dan perancangan sistem interaksi pada instalasi ini. Interaktivitas dalam instaslasi ini dibangun menggunakan teknologi motion capture dan sensor Kinect. Komposisi musik yang berupa nyanyian Tari Saman, bunyibunyian hasil gerakan Tari Saman dan instrumen musik lainnya, yang berasal dari MIDI controller, direkam menggunakan software GarageBand. Desain visual dan user interface dibuat dengan melakukan stilasi terhadap ragam hias kain kerawang Gayo. Dimulai dari bentuk sketsa, proses editing dan finalisasi menggunakan komputer. Pada akhirnya, masing-masing elemen di atas akan digabungkan menjadi satu ke dalam sebuah instalasi interaktif komposisi musik dan visual dengan studi kasus Tari Saman.

\section{HASIL DAN PEMBAHASAN}

\section{Konsep Perancangan}

Konsep umum dari instalasi interaktif komposisi musik dan visual ini adalah penggabungan teknologi dan unsur budaya lokal untuk menjaga kelestarian budaya dan menjaga nilai-nilai identitas bangsa Indonesia. Dalam usaha untuk mewujudkan gagasan tersebut, maka dipilihlah Tari Saman sebagai studi kasus perancangan ini. Unsur Tari Saman yang diangkat adalah musik Tari Saman yang terdiri dari nyanyian Saman dan gerak tangan penari yang menghasilkan bunyi, serta ragam hias kerawang Gayo dalam kostum penari Saman. Sementara itu, konsep interaktivitas dalam instalasi ini dibuat dengan menggunakan teknologi motion 
capture dan sensor Kinect dikemas melalui sebuah media instalasi.

Adapun tujuan perancangan instalasi interaktif ini adalah membangun sebuah sistem perangkat yang menerjemahkan gesture menjadi musik dan visualisasi, menggunakan konsep real-time interaction. Selain itu, instalasi interaktif ini juga dirancang sebagai ruang ekspresi yang mengeksperimentasi teknologi dengan mengangkat konten budaya lokal. Diharapkan perancangan ini dapat menjadi alternatif permainan untuk membuat komposisi musik dan visual. Berbeda dari permainanpermainan yang sudah ada sebelumnya, dalam instalasi interaktif ini, user mengontrol sistem, bukan sistem yang mengontrol user.

Merujuk pada fungsi dari instalasi interaktif ini sebagai permainan komposisi musik dan visual, maka instalasi ini diberi judul Oncé yang dalam bahasa Sansekerta berarti karangan atau gubahan. Secara garis besar, user diberikan alternatif pilihan bunyi untuk membuat sebuah komposisi lagu utuh. Pemilihan elemen-elemen bunyi tersebut lah yang akan memunculkan elemen-elemen visual. Jika keseluruhan tahapan dalam pemilihan elemen bunyi sudah terpenuhi, maka secara tidak langsung, user pun membuat sebuah komposisi visual yang utuh.

\section{Konsep Media Interaktif}

Perancangan instalasi interaktif komposisi musik dan visual dengan studi kasus Tari saman ini mencakup tiga komponen utama, yaitu perangkat komputer, Kinect sebagai sensor dan gerakan manusia. Tiga komponen di atas saling berkaitan mulai dari proses pendeteksian skeleton user dan trigger dari user dengan menekan virtual button yang ditangkap oleh Kinect, untuk kemudian diproses menggunakan software programming dan disimpan ke dalam komputer dalam bentuk data digital. Input dalam instalasi ini yang berupa gesture dari user akan menghasilkan output berupa musik dan visual.

Secara sederhana dapat dijelaskan bahwa instalasi ini memiliki fokus pada interaksi fisik antara manusia dengan sistem. Interaksi antara manusia dan sistem adalah proses dua arah, yaitu kontrol dan umpan balik. Interaksi tersebut terjadi melalui perantara interface yang diterjemahkan dari tindakan dunia nyata menjadi sinyal ke dalam sistem. Pada akhirnya, interaksi yang terjadi antara user dengan sistem diharapkan dapat menstimulasi gerak motorik, indera pendengaran dan penglihatan, sehingga user dapat merasakan sensasi dan memunculkan persepsi warna, bentuk, dan lain sebagainya. 


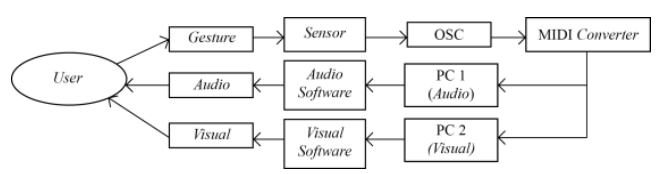

Gambar 1 Konsep Interaktivitas dalam Instalasi (Carolline, 2014)

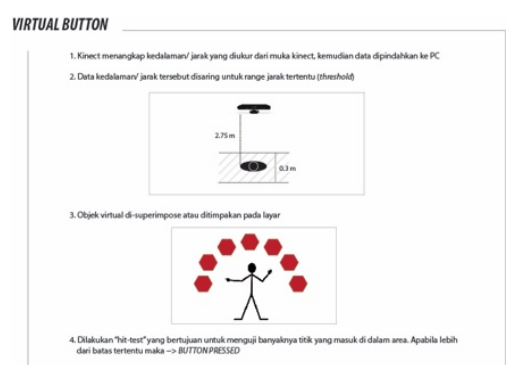

Gambar 2 Cara Kerja Kinect dan

Virtual Button (Carolline, 2014)

\section{Konsep Pemrograman}

Dalam konsep algoritma pemrograman, terdapat beberapa langkah yang dilakukan oleh programmer dalam menetukan konsep pemrograman, diantaranya adalah mendefinisikan masalah, mencari solusi, menentukan algoritma, menulis program, menguji program, mendokumentasikan program dan merawat program. Platform yang digunakan programmer dalam konsep pemrograman ini adalah Microsoft Windows 7. Sementara development tool-nya adalah Microsoft Visual C++ 2010 Express.

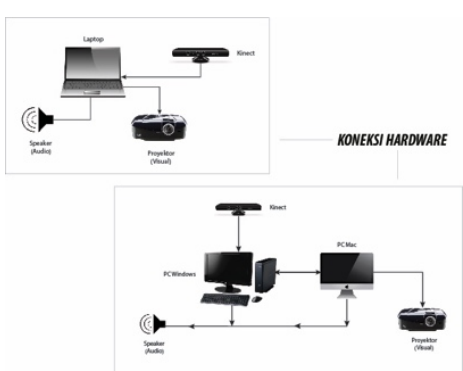

Gambar 3 Koneksi Hardware

(Carolline, 2014)

\section{Perancangan Instalasi}

Tahapan ini adalah tahap merealisasikan pembuatan instalasi interaktif komposisi musik dan visual dengan studi kasus Tari Saman. Pada tahap ini dilakukan proses pembuatan elemen-elemen musik yang akan dijadikan sebuah komposisi, serta dilakukan visualisasi desain semua aset instalasi. Aset-aset tersebut adalah logo, tampilan latar, tombol navigasi, elemen visual dan layouting. Setelah tahap ini dikerjakan, tahap selanjutnya adalah pemrograman, agar instalasi dapat berfungsi sesuai dengan konsep perancangan.

\section{Musik}

Musik berkaitan dengan indera pendengaran. Pesan yang akan disampaikan dalam instalasi ini dituangkan ke dalam lambanglambang auditif baik verbal maupun non verbal. Tari Saman merupakan tarian yang unsurunsur di dalamnya berkesinambungan dengan unsur utama musik seperti tempo, melodi, harmoni dan bentuk struktur lagu. Ragam musik dalam komposisi musik instalasi Oncé ini termasuk ragam musik tradisional karena merupakan eksplorasi dari nyanyian Tari Saman. Selain nyanyian Tari Saman, komposisi musik dalam instalasi ini juga digabungkan dengan elemenelemen musik digital sebagai pendukung, sehigga dihasilkan aransemen lagu yang utuh. 
Ragam nyanyian Tari Saman yang digunakan dalam komposisi musik instalasi Oncé adalah rengum, syek, saur. Sementara itu, elemen bunyi hasil gerakan Tari Saman yang digunakan dalam komposisi musik instalasi Oncé adalah tepukan kedua belah tangan, pukulan kedua telapak tangan ke dada dan gesekan ibu jari dengan jari tengah. Selain bunyi-bunyian yang sudah disebutkan, terdapat pula elemen musik digital yang digunakan dalam instalasi ini berdasarakan unsur musik, diantaranya adalah irama (rebana, tabla, shaker, tepukan tangan), melodi (vokal 1 , vokal 2, vokal 3, vokal 4), harmoni (ode, tampura, tarompet, string), bunyi dan nada (pitch, efek digital).

Aransemen atau struktur lagu dalam instalasi Oncé yang digubah terinsipirasi dari unsur-unsur yang terdapat pada Tari Saman. Dibantu oleh seorang komposer musik, komposisi musik ini direkam menggunakan software Garageband. Adapun struktur lagu untuk komposisi musik dalam instalasi Oncé ini adalah sebagai berikut:

1. Bentuk struktur lagu:

$$
\begin{array}{ll}
\text { - } & \text { Intro } \\
\text { - } & \text { Verse } 1 \\
\text { - } & \text { Verse II } \\
\text { - } & \text { Reffrain } \\
\text { - Outro }
\end{array}
$$

2. Elemen musik: rekaman nyanyian Tari Saman (rengum, syek, saur), rekaman tepukan tangan Tari Saman dan elemen musik digital/ MIDI
3. Irama: $4 / 4$

4. Tempo: 120

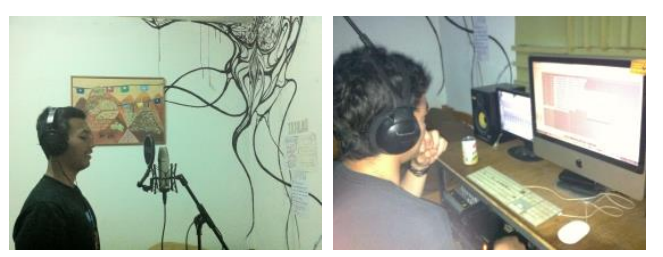

Gambar 4 Proses Pembuatan

Komposisi Musik Instalasi Oncé

(Carolline, 2014)

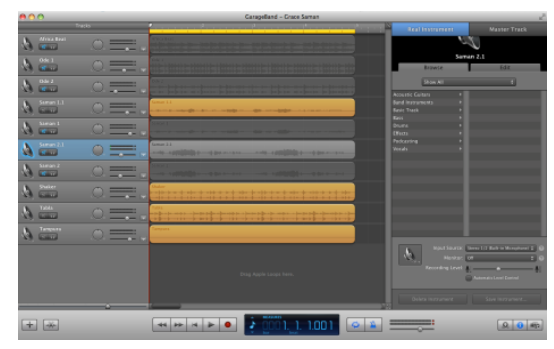

Gambar 5 Software Garageband

(Carolline, 2014)

\section{Visual}

Komponen visual dalam instalasi ini merupakan hasil eksplorasi dari kostum penari Saman, yaitu kain kerawang Gayo. Proses pembuatan komposisi visual ragam hias kerawang Gayo dilakukan dengan melalui beberapa tahapan, yaitu: menentukan pilihan ragam hias, penggambaran bangun luar, menyempurnakan dan melengkapi bagian-bagian bangun luar, pemberian aksen dan finishing. Pembuatan komposisi visual instalasi Oncé ini menggunakan teknik stilasi. Stilasi ragam hias pada kain kerawang Gayo dilakukan untuk menghasilkan ragam hias baru yang unik sebagai elemen visual dari instalasi. Stilasi adalah jenis gambar yang menyederhanakan bentuk dengan 
tidak meninggalkan karakter bentuk aslinya. Ragam hias kerawang Gayo yang dieksplorasi dalam pembentukan komposisi visual instalasi interaktif ini adalah ragam hias emun berangkat, pucuk ni rebung, puter tali, ulen-ulen dan tapak seleman. Adapaun langkahlangkah pembuatan komposisi visual instalasi interaktif yang menggunakan ragam hias kerawang Gayo adalah sebagai berikut:

1. Menentukan pilihan ragam hias

2. Penggambaran bangun luar

3. Menyempurnakan dan melengkapi bagian-bagian bangun luar

4. Pemberian aksen

5. Finishing

Terdapat tiga komponen visual dalam instalasi ini, yaitu: komponen visual untuk environment/background, elemen komposisi visual instalasi dan komponen visual untuk desain interface. Dalam instalasi Oncé ini, unsur visual merupakan output dari input user yang berupa gestur. Interaksi antara user dengan sistem dalam instalasi Oncé ini dirancang sedemikian rupa selain untuk menghasilkan komposisi musik, juga untuk menghasilkan komposisi visual.

\section{Tabel 1 Stilasi Ragam Hias Kerawang Gayo}

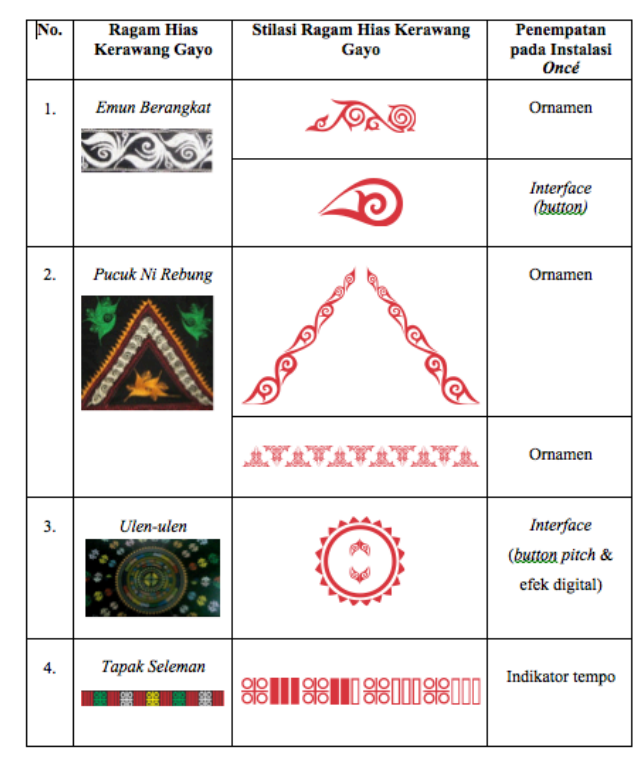

(Carolline, 2014)

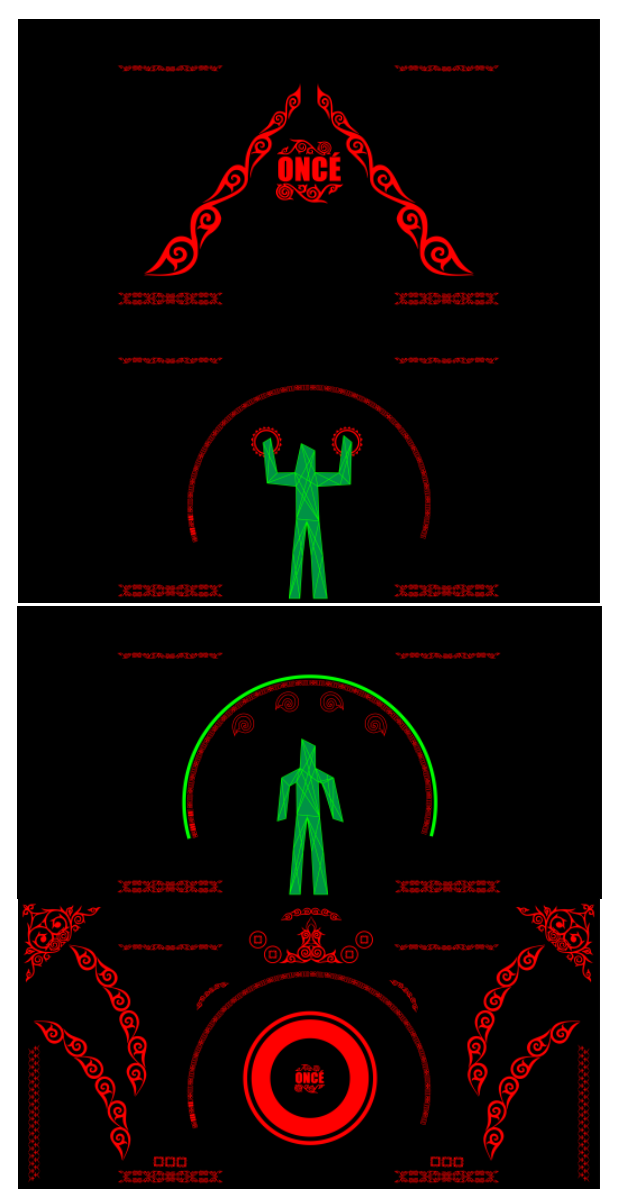

Gambar 6 Visualisasi Instalasi Oncé (Carolline, 2014) 


\section{Perancangan dan Uji Coba Sistem}

Selain proses desain, dilakukan pula perancangan sistem dan eksperimen atau uji coba pada sistem instalasi interaktif ini. Adapun beberapa uji coba yang dilakukan adalah sebagai berikut:

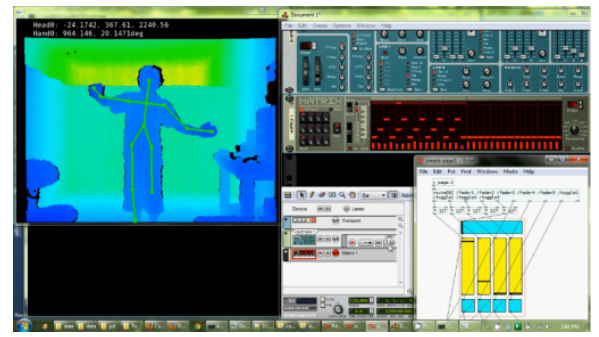

Gambar 7 Perancangan dan Uji

Coba Sinkronisasi Kinect dengan

MIDI Controller (Carolline, 2014)

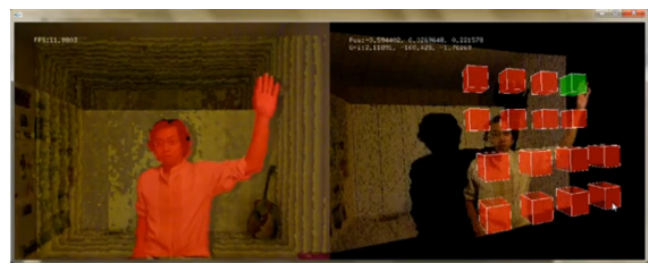

Gambar 8 Perancangan dan Uji

Coba Kinect Virtual Button - PoC

(Carolline, 2014)

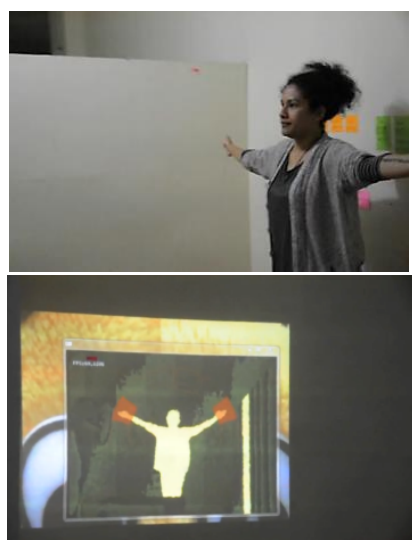

Gambar 9 Perancangan dan Uji

Coba Air Keyboard - PoC (Carolline, 2014)

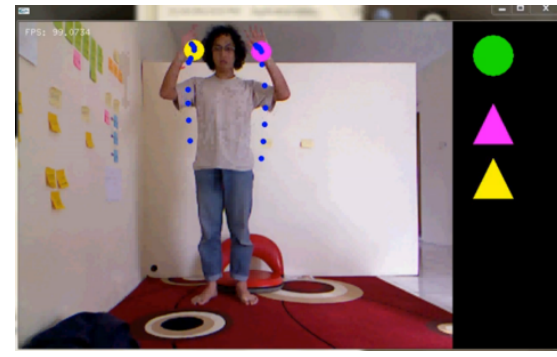

Gambar 10 Perancangan dan Uji

Coba Gestural Control

menggunakan Kinect (Carolline, 2014)

\section{Struktur Permainan Instalasi Oncé}

Struktur permainan dalam instalasi ini merujuk pada unsur-unsur yang selalu ada dalam sebuah game (Fullerton, 2008: 26-44) yang sering disebut sebagai formal elements. Adapaun unsur-unsur tersebut diterapkan dalam instalasi Oncé, sebagai berikut:

1. Pemain (player)

Dalam permainan komposisi musik dan visual ini pemain berjumlah 1 orang.

2. Tujuan (objectiveness)

Tujuan dari permaianan dalam instalasi ini adalah membuat komposisi musik dan komposisi visual.

3. Aturan (rules)

Player akan diberikan empat pilihan tampilan background, masing-masing backgroud terdiri dari empat buah button yang berisi elemenelemen musik. Player diwajibkan untuk memilih masing-masing satu button di tiap background. Tiap 
button tersebut apabila dipilih akan menghasilkan visual yang berbeda-beda pula.

4. Cara bermain (procedures) Player diwajibkan berdiri di titik yang telah disediakan karena ada keterbatasan jarak tangkap dari sensor Kinect. Setelah itu player diarahkan untuk melakukan psy-pose dalam pendeteksian skeleton player oleh sensor Kinect. Setelah player berhasil dideteksi oleh Kinect, player diberi tampilan virtual button. Player diberikan kebebasan untuk memilih virtual button mana yang akan diaktifkan.

5. Objek Bermanfaat (resources) Objek bermanfaat dalam permaianan ini adalah waktu. Di tiap tahapan permainan, terdapat waktu yang telah ditentukan. Sistem pun akan secara otomatis mengganti background apabila waktu pada background sebelumnya sudah habis.

6. Masalah (conflict)

Masalah akan terjadi saat permainan dimulai. Player diberikan batasan waktu saat bermain, mulai dari background pertama, sampai background terkahir. Terdapat indikator waktu yang muncul di layar. Apabila player kehabisan waktu, maka permainan pun tidak bisa dilanjutkan ke tahapan selanjutnya, atau bisa dikatakan game over.

7. Batasan (boundaries)

Permainan ini dibatasi dengan menggunakan gestur player sebagai trigger dalam membuat komposisi musik dan visual.

8. Hasil akhir (outcome) Apabila player berhasil melewati tahapan awal sampai akhir permainan, maka player tersebut telah membuat komposisi musik dan komposisi visual. Komposisi musik yang berubah sebuah lagu utuh dan sebagai reward, tahap pada akhir permainan akan muncul button dengan fitur record. Player dapat mendapatkan lagu hasil komposisi mereka dalam format mp3.

\section{Produk Akhir}

Produk akhir eksperimentasi perancangan ini adalah sebuah instalasi interaktif komposisi musik dan visual dengan studi kasus Tari Saman. Setelah melalui rangkaian proses penelitian dan perancangan, maka hasil akhirnya adalah sebuah karya instalasi interaktif yang diberi judul Oncé. 


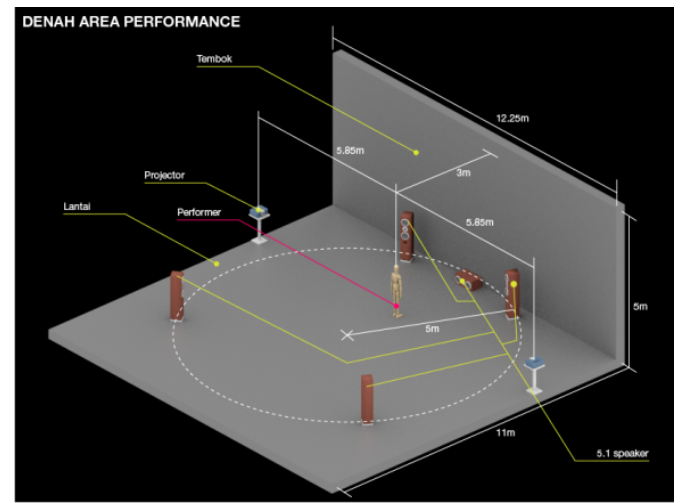

Gambar 11 Denah Area Instalasi

Oncé (Carolline, 2014)

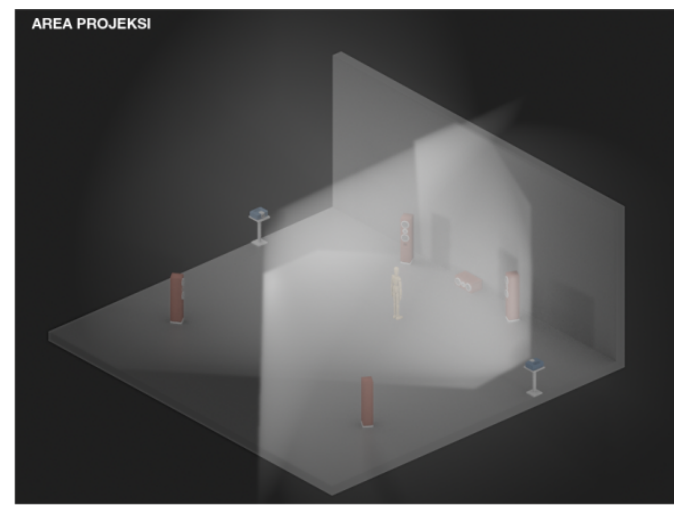

Gambar 12 Denah Area Proyeksi

(Carolline, 2014)

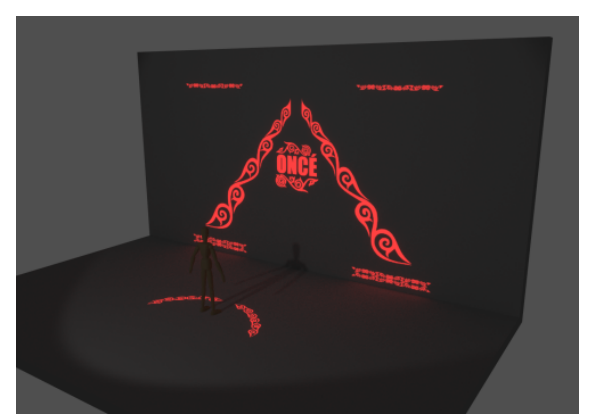

Gambar 13 Tampilan Awal

Instalasi Oncé (Carolline, 2014)

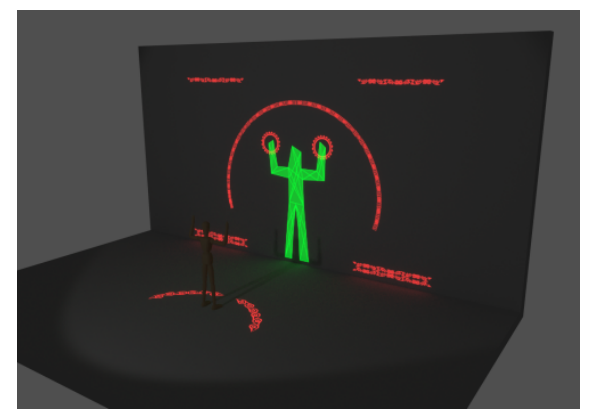

Gambar 14 Tampilan Tahap Psypose User (Carolline, 2014)

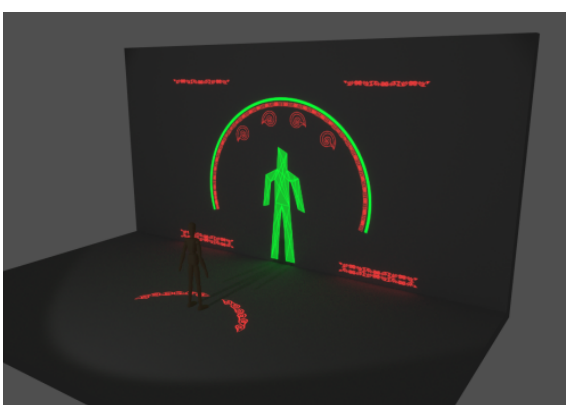

Gambar 15 Tampilan Saat Permainan Dimulai (Carolline, 2014)

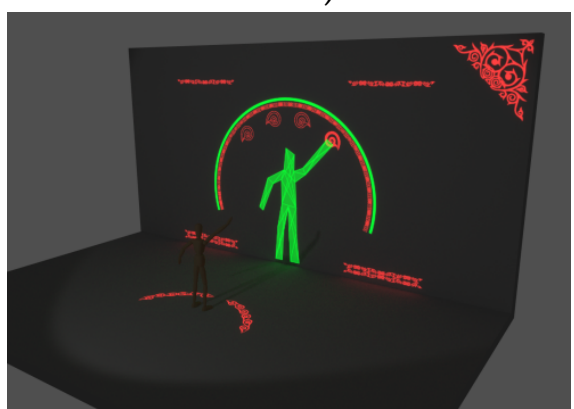

Gambar 16 Tampilan Background I (Carolline, 2014)

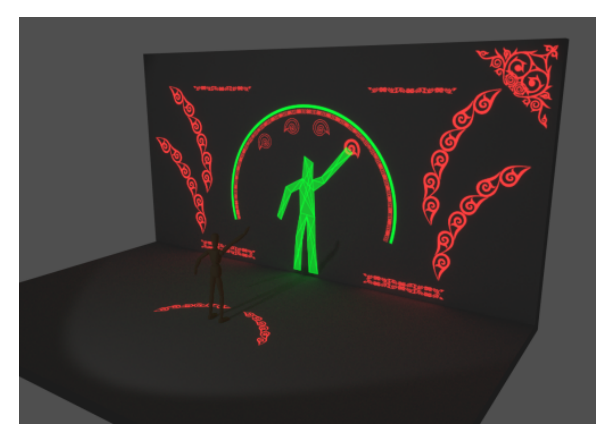

Gambar 17 Tampilan Background II (Carolline, 2014)

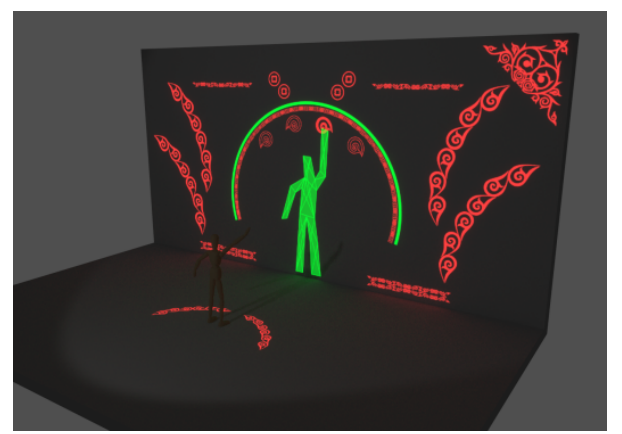

Gambar 18 Tampilan Background III (Carolline, 2014) 


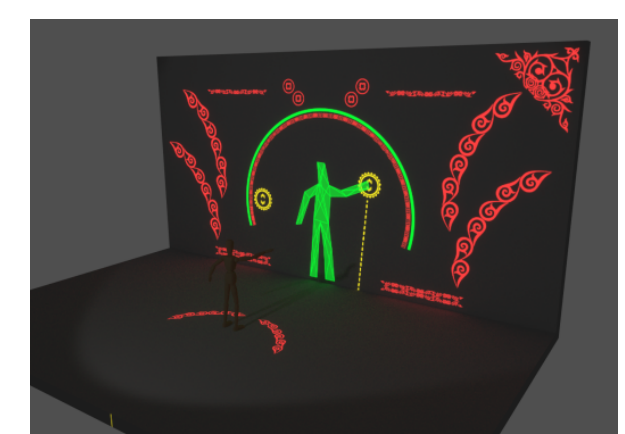

Gambar 19 Tampilan Background IV (Carolline, 2014)

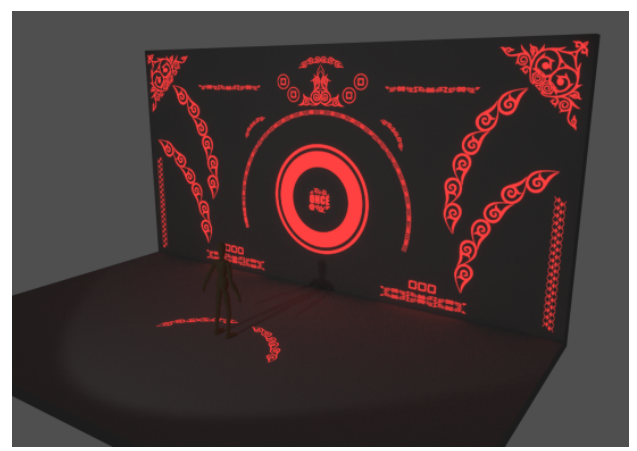

Gambar 20 Tampilan Akhir Instalasi Oncé (Carolline, 2014)

\section{KESIMPULAN}

Interaksi real-time antara manusia dengan sistem dalam instalasi interaktif komposisi musik dan visual dengan studi kasus Tari Saman, berjudul Oncé, merupakan bagian dari teknologi interaction design. Gestur yang berasal dari user menjadi input bagi sistem yang menghasilkan ouput berupa musik dan visual. Dialog antara user dengan sistem ini sangat dipengaruhi oleh peran desain interface. Perancangan desain interface yang informatif dan menarik memudahkan user dalam menangkap pesan, sehingga interaksi yang diharapkan terjadi pun terwujud dalam instalasi Oncé ini.
Penggunaan teknologi motion capture dengan sensor Kinect pada instalasi interaktif komposisi musik dan visual yang mengangkat unsur musik Tari Saman dan visual ragam hias kerawang Gayo ini dinilai efektif. Faktor penting dalam penggunaan Kinect adalah penempatan Kinect pada ruangan dengan pencahayaan yang sesuai agar saat proses perekaman gerak tidak terjadi noise yang dapat mengurangi keakuratan. Selain itu jarak Kinect pun perlu diperhatikan sehingga proses pembacaan ruang gerak dapat berlangsung dengan baik. Setelah melalui beberapa tahap eksperimen dan uji coba, sensor Kinect dalam membaca data gerakan secara real-time pun berfungsi dengan baik sehingga dapat mewujudkan tujuan dari perancangan instalasi interaktif ini.

Penggabungan budaya lokal, dalam hal ini Tari Saman, dengan teknologi yang digunakan pada instalasi interaktif komposisi musik dan visual ini dilakukan dengan mengambil unsur-unsur yang khas dalam Tari Saman tersebut. Dalam komposisi musik, unsur khas yang diambil adalah nyanyian Tari Saman dan bunyi-bunyian yang berasal dari gerakan tangan para penari Saman. Kemudian elemenelemen musik tersebut dipadukan dengan musik digital sebagai perantara unsur modern dan tradisional. Sedangkan dalam komposisi visual, dilakukan stilasi 
ragam hias kerawang Gayo yang kemudian dikomposisikan berdasarkan prinsip persepsi visual. Faktor keseimbangan, harmoni, pola dan irama dalam komposisi visual ini menimbulkan persepsi tersendiri bagi user instalasi Oncé.

Perwujudan instalasi interaktif komposisi musik dan visual dengan studi kasus Tari Saman yang masih bersifat prototype ini, diharapkan dapat menjadi alternatif perkembangan multimedia interaktif di Indonesia, serta dapat turut melestarikan budaya bangsa. Unsur budaya lokal yang dikemas dengan teknologi diharapkan pula dapat menarik perhatian generasi muda dalam rangka melakukan upayaupaya tersebut.

Pada pelaksanaannya, perancangan instalasi ini melibatkan interdisiplin yang dikerjakan oleh sebuah tim yang di dalamnya terdiri dari programmer, music composer dan multimedia artist. Kerjasama dengan berbagai orang dengan latar belakang yang berbeda namun saling menunjang dapat mempermudah dan mempercepat proses perancangan. Dalam bidang akademik kolaborasi antar disiplin ilmu menjadi sangat penting karena masing-masing bidang tidak dapat berdiri sendiri. Alangkah baiknya jika masing- masing disiplin ilmu dapat saling berkolaborasi sehingga dapat saling melengkapi dalam menghasilkan sebuah produk atau karya yang unggul.

Konsep interaksi yang menggabungkan unsur gestur, audio dan visual ini dapat diteliti dan dikembangkan lebih lanjut sehingga dapat menghasilkan produk dan juga bermanfaat dalam bidang-bidang lain, seperti pendidikan, kesehatan, dan sebagainya. Pembuatan instalasi interaktif ini juga dapat diterapkan dengan menggunakan unsur budaya lokal lain, seperti karawitan Sunda, dsb.

\section{Daftar Pustaka}

2008. Fullerton, Tracy. Game Design Workshop: A Playcentric Approach to Creating Innovative Games. Second Edition. Morgan Kaufmann Publisher, USA.

1985. Koentjaraningrat. Pengantar Antropologi Budaya. Jakarta: Aksara Baru.

1952. Kroeber, Alfred. The Nature of Culture. Chicago: University of Chicago Press.

2008. Schell, Jesse. The Art of Game Design.

Amsterdam: Elsevier.

2011. Vaughan, Tay. Multimedia: Making It Work. 8th edition. New York: McGraw Hill 